\title{
Faces e Funções: o (Des)uso do PPA a PARTIR de suas funcionalidades e a INSTABILIDADE ORÇAMENTÁRIA ${ }^{1}$
}

Leandro Freitas Couto ${ }^{2}$

\section{INTRODUÇÃO}

A Constituição Federal de 1988 (CF/1988) estabeleceu o Plano Plurianual (PPA) como o principal instrumento de planejamento de médio prazo, a fim de orientar as peças orçamentárias anuais, com o intermédio da Lei de Diretrizes Orçamentárias (LDO). Todavia, a ausência de uma lei complementar de finanças, ao lado do surgimento de novos arranjos de governança orçamentária desde a promulgação da Constituição, fez com que o PPA assumisse diferentes funçóes ao longo do tempo.

O planejamento público não pode ser confundido com o ato de fazer planos. Ao contrário, o exercício do planejamento é muito mais abrangente, confundindo-se com o próprio ato de governar. Definir objetivos e metas, estabelecer as estratégias, com o envolvimento da articulação e do mapeamento da posição dos atores, para a implementação das políticas, contemplando a definição de fontes e formas de financiamentos, além das atividades de monitoramento e avaliação, compõe uma gama de atividades que se enquadram no arcabouço do planejamento.

Ao PPA, como principal instrumento de médio prazo do planejamento governamental no Brasil, foram atribuídas algumas dessas atividades, com alterações de ênfases e foco ao longo do tempo. Essa busca por espaço no arranjo de planejamento e orçamento é retrato da sua baixa incidência sobre o processo alocativo de forma mais direta, ainda que seja possível afirmar que o PPA tenha influenciado o orçamento em vários momentos (Couto e Cardoso Junior, 2020a).

O objetivo deste artigo é apresentar a evolução das funçóes que o PPA foi assumindo ao longo do tempo, refletindo sobre seus espaços na governança orçamentária atual. Nessa linha, ainda apresenta algumas reflexôes acerca da proposta de extinção do PPA e a instituição de um orçamento plurianual. A principal hipótese considerada na pesquisa é que as limitações do PPA não se circunscrevem apenas às características do instrumento, mas também estão fortemente relacionadas ao desenho do processo orçamentário.

Para tanto, o artigo se divide em três seções, além desta introdução e da conclusão. Inicialmente, apresentam-se as funçóes de planejamento que o PPA incorporou ao longo dos anos. Em seguida, encontram-se as questóes relevantes sobre a incidência e confluências dos processos do PPA e do orçamento, ressaltando as possibilidades de articulaçáo. Por fim, discutem-se as questóes atuais advindas das recentes mudanças nas regras orçamentárias relacionadas ao Novo Regime Fiscal, à obrigatoriedade de execução das emendas parlamentares e à proposta de extinção do PPA e instituição de um orçamento plurianual.

1. DOI: http://dx.doi.org/10.38116/bapi27art2

2. Analista de planejamento e orçamento; e pesquisador em exercício na Diretoria de Estudos e Políticas do Estado, das Instituições e da Democracia (Diest) do Ipea. 


\section{PPA E SUAS FUNÇÕES}

Os primeiros PPAs pós-Constituição referentes aos períodos 1991-1995³ e 1996-1999 não tinham uma relação nítida com o orçamento. Serviam mais como carta de intençóes, com uma lista de objetivos, diretrizes e projetos, sem um processo de gestão específico, que envolvesse a tomada de decisão alocativa para o curto prazo.

Em paralelo ao PPA 1996-1999, definiu-se uma lista de projetos prioritários, com um processo de gestão específico, emoldurado dentro de um programa de investimentos - Brasil em Ação. Conforme Barzelay e Shvets (2005), o Brasil em Ação tinha três pilares: uma estratégia de gestão baseada na figura de um gerente para cada projeto, o controle do fluxo financeiro dos projetos e um sistema de informaçóes que dava suporte ao fluxo de comunicação necessário.

Essa iniciativa do Brasil em Ação converge para o momento em que a agenda da Nova Gestão Pública (NGP) se ensaiava no Brasil, principalmente a partir do Plano Diretor da Reforma do Aparelho do Estado (PDRAE), patrocinado pelo então ministro Bresser-Pereira. Conforme demonstram Couto e Cardoso Junior (2020b), embora o planejamento não fosse um elemento central na agenda de reforma do Estado, foi justamente a reformulação do PPA que permitiu a realização de algumas das mudanças previstas para a gestão e o processo orçamentário.

Essa reformulação do PPA foi construída a partir da produção de um Grupo de Trabalho Interministerial, constituído para discutir o projeto de lei complementar de finanças públicas - que segue, até 2020, sem aprovação por parte do Congresso Nacional. Resultado desse esforço foi o Decreto no 2.829/1998, que instituiu as normas para elaboração e execução do PPA e dos orçamentos da União. A partir daí, a lógica de integração entre plano e orçamento se alterou, processando-se uma primeira tentativa de construção de orçamento por programas.

Esse processo culmina, portanto, com novas funções atribuídas a esse instrumento de planejamento, que vão também se alterando ao longo dos anos. Couto e Cardoso Junior (2020a) resgataram essas funçóes, que podem ser condensadas da seguinte forma.

\section{Gestão de prioridades}

O modelo de gestão do Brasil em Ação foi apropriado no PPA 2000-2003 para um conjunto de programas considerados estratégicos no plano. Todos os cerca de 350 programas tinham gerentes, mas apenas os 67 prioritários contavam com processos de gestão do fluxo financeiro e gestão de restrições. Todavia, com a crise financeira que se abateu sobre o país no final dos anos 1990, e as restriçóes fiscais impostas pela Lei de Responsabilidade Fiscal (LRF), promulgada pouco meses antes da aprovação do PPA, teve sua aplicação limitada.

Para o PPA seguinte, essa função de gestão de prioridades seria abandonada, visto que seu arranjo, principalmente após a criação do Programa de Aceleração do Crescimento (PAC), distancia-se do PPA e mesmo do Sistema de Planejamento e de Orçamento Federal (SPOF) (Couto e Magalhães, 2017).

3. Com o impeachment de Fernando Collor, o governo Itamar Franco chegou a enviar uma proposta de revisão do PPA ao Congresso Nacional que não chegou a ser aprovada. 


\section{Planejamento e gestão territorial}

A experiência do Brasil em Ação também encaminhou a retomada do planejamento territorial, com a elaboração do Estudo dos Eixos Nacionais de Integração e Desenvolvimento, os quais se desenhavam a partir dos projetos estruturantes do programa anterior, buscando oportunidades de investimentos complementares, articulados ao redor de projetos-âncora.

Ainda que fortemente centrado em projetos de infraestrutura e conferindo pouca importância ao papel das cidades na articulação do território, esse estudo reforçava a inserção da dimensão territorial no planejamento, presente no PPA 2000-2003, com a indicação de uma carteira de médio prazo (oito anos) para o país, que deveria ser escalonada nos sucessivos PPAs.

O PPA seguinte buscou avançar, por sua vez, em uma estratégia de gestão territorial, trabalhando novas escalas territoriais com "pactos de concertamento". Essa experiência se bastou em alguns pilotos, mas foi novamente retomada no PPA 2012-2015, com as agendas de desenvolvimento territorial.

\section{Avaliação e análise ex ante}

O PPA 2004-2007 trouxe uma proposta de constituição de um Sistema de Monitoramento e Avaliação, com a criação de uma Comissão de Monitoramento e Avaliação (CMA), coordenada pelo órgáo central de planejamento do SPOF, e pelas unidades de monitoramento e avaliação, nos órgãos setoriais. Entre outras, uma de suas principais funçôes seria realizar análises ex ante para a inclusão de projetos no orçamento ou antes da liberação do empenho orçamentário dos projetos.

Esse processo foi interditado com o PAC, mas retomado em 2016, com a instituição da Comissão de Monitoramento e Avaliação de Políticas Públicas (CMAP), ainda, inicialmente, não formalmente vinculada ao PPA. Nesse período, houve um reforço dos instrumentos de avaliação, com a edição de guias de análise ex ante, ex post e avaliação de impacto regulatório, capitaneados pela Casa Civil, no bojo do processo de adesão à Organização para a Cooperação e Desenvolvimento Econômico (OCDE). Para o PPA 2020-2023, no entanto, essa ligação é formalizada, e as avaliações das políticas públicas constantes do PPA seriam realizadas pela CMAP, sendo a aproximação entre planejamento e avaliação uma das principais apostas deste PPA.

\section{Gestão de transversalidades}

O PPA 2012-2015 deu destaque às agendas transversais, para as quais se constituiu um processo de gestão participativa, via Fórum Interconselhos. Ainda que focadas em públicos específicos (mulheres, crianças e adolescentes, juventude, população em situação de rua, povos indígenas, negros, idosos, LGBT) e fortemente relacionadas às políticas sociais, essas agendas ocuparam espaço central na estratégia de gestão do plano, que havia sido reestruturado em torno de programas temáticos.

Como demonstram Rodrigues e Xavier (2017, p. 100), contudo, é possível identificar as transversalidades como orientação da gestão governamental desde o PPA 2004-2007. Para as autoras, “as definiçóes e os exemplos de 'temas transversais' adotados nos instrumentos de elaboração e gestão do PPA 2004-2007 indicavam que 'temas transversais' eram todos os problemas complexos e multifacetados, para os quais era exigida do governo a atuação articulada dos diversos órgãos da administração pública federal”. 
Criticam, assim, a limitação dos temas considerados transversais no PPA 2012-2015, o que foi parcialmente superado no PPA 2016-2019, quando da indicação de temas como o uso múltiplo da água, economia solidária e desenvolvimento rural sustentável também como agendas transversais. Mais ainda, no PPA 2016-2019, buscou-se também refletir os Objetivos de Desenvolvimento Sustentável (ODS), que se constituíam por meio de transversalidades e multissetorialidades.

\section{Planejamento e gestão participativos}

O PPA 2004-2007 trouxe uma abordagem participativa, com a construção de um processo de planejamento que envolvia a sociedade na definição das orientaçóes estratégicas do PPA. O processo deveria seguir com um desenho de participação social também na gestão dos programas, o que acabou se revelando frágil. O PPA 20082011 abandonou essa perspectiva, reforçando os mecanismos já institucionalizados de participação social nas políticas setoriais, por meio dos conselhos nacionais. O PPA deixava de se constituir em um canal especial de participação social.

No PPA 2012-2015, a participação social foi retomada e se deu de forma bastante incisiva via Fórum Interconselhos, tanto nos momentos de elaboração quanto de gestáo do plano. Foi nesse espaço que os conselhos definiram quais as agendas transversais seriam objeto de gestão participativa, por exemplo. A partir dessa experiência, também se buscou uma incidência no processo orçamentário, principalmente a partir da "reforma orçamentária" de 2013, que promoveu uma aglutinação de açóes e a criaçáo dos planos orçamentários.

O quadro 1 retrata os diferentes planos, a partir de 2000, com suas respectivas funçóes associadas.

QUADRO 1

PPAs e principais funções de planejamento associadas

\begin{tabular}{|l|l|}
\hline \multicolumn{1}{|c|}{ PPA } & \multicolumn{1}{|c|}{ Funções } \\
\hline PPA 2000-2003 & Gestão de prioridades \\
\hline PPA 2004-2007 & $\begin{array}{l}\text { Gestão territorial } \\
\text { Avaliação }\end{array}$ \\
\hline PPA 2008-2011 & $\begin{array}{l}\text { Planejamento e gestão participativa } \\
\text { Gestão territorial } \\
\text { Agendas transversais }\end{array}$ \\
\hline PPA 2012-2015 & Agendas transversais e ODS \\
\hline PPA 2016-2019 & Avaliação \\
\hline PPA 2020-2023 & \\
\hline
\end{tabular}

Elaboração do autor.

\section{A LIGAÇÃO COM O ORÇAMENTO}

Ao absorver várias funçóes atinentes ao planejamento, o PPA buscava contribuir de diferentes formas na gestão das políticas públicas, inclusive no processo de orçamentação. Segundo Couto e Cardoso Junior (2020a), isso se deu de forma mais direta quando do controle de fluxo financeiro dos projetos prioritários, quando lhe foi atribuída a gestão de prioridades, no PPA 2000-2003. No entanto, vale lembrar que no mesmo ano de aprovação do PPA, a promulgação da LRF conferiu maior centralidade à LDO, com relação às metas de resultado primário, no processo orçamentário, alijando o PPA (Couto e Rodrigues, 2020). 
Com relação ao formato do orçamento, o PPA 2000-2003 teve incidência direta. Com a mudança de metodologia, para o PPA 2012-2015, também foi possível processar uma nova mudança no orçamento, ocorrida para 2013. No mesmo ano, os processos participativos que tomaram corpo no PPA também alcançaram o orçamento, na discussão da LDO (Avelino, 2017).

De fato, a relação se estruturou a partir da adoção do programa como unidade de gestão, no PPA 2000-2003. Todavia, como aponta Garcia (2015), a estratégia de construção de um inventário de açôes já existentes para "encaixar" na nova programação trouxe limitaçôes importantes, sendo possível afirmar que, de fato, o Brasil não conseguiu implantar um orçamento por programa, com foco em resultados.

A metodologia do PPA adotada entre 2012 e 2019 abandonou essa perspectiva. A aglutinação das ações orçamentárias, com maior ocorrência de "açôes guarda-chuva" (linhas orçamentárias que abrigam várias possibilidades de entregas ou produtos genéricos), fortaleceu esse movimento, que não foi recuperado com o PPA 2020-2023.

A partir de 2012, as açóes orçamentárias deixaram de fazer parte do Plano. Como suas metas e objetivos não tinham uma relação direta com o orçamento, essa relação se torna turva. Além disso, os indicadores dos programas não mais tinham relação direta com os seus objetivos, não apresentando metas pretendidas para evoluçáo de resultados, mas um conjunto relevante de dados de monitoramento da situação do tema - ainda que não fossem diretamente afetados pela intervenção governamental.

A flexibilização da execução do gasto proveniente da aglutinação de açóes, a partir de 2013, foi acompanhada de novas regras que engessaram o gasto primário. Nesse ponto, é necessário listar o novo regime fiscal atribuído pela Emenda Constitucional no ${ }^{95}$, que impóe um teto para o crescimento dos gastos primários. Por sua vez, a instituição da obrigatoriedade de execução das emendas parlamentares, individuais e de bancada, criou novos comandos prioritários ao orçamento, deixando o PPA cada vez mais distante.

Em verdade, o orçamento seguiu sua própria dinâmica, alimentado pelo planejamento setorial, dependente das capacidades de cada unidade, ao passo que o próprio órgáo central de planejamento é fragilizado - a Secretaria de Planejamento e Investimentos Estratégicos (SPI) é extinta em 2017, sendo fundida com a assessoria econômica do então Ministério do Planejamento, Desenvolvimento e Gestão, e, em 2019, é rebaixada para subsecretaria de planejamento, dentro da Secretaria de Avaliação de Políticas Públicas, Planejamento, Energia e Loterias (Secap).

Assim, as funçóes de planejamento apropriadas pelo PPA tiveram pouca incidência no orçamento, justamente por conta da distinção entre os dois processos. A exceção é a gestão estratégica, porque atuava em conjunto com o processo de execução do orçamento. Da mesma forma, quando realizada no âmbito do PAC, alimentado pelo planejamento setorial, também incidia fortemente sobre o orçamento. O ponto aqui a ser observado é a ausência do PPA nesse circuito, o que não deve ser confundido com ausência de planejamento.

Nessa linha, a incidência do PPA na própria identificação das metas e prioridades da LDO é baixa ou nula. A avaliação e o monitoramento do PPA também tiveram pouca incidência direta sobre o orçamento, ainda que, como partes do planejamento setorial, podem ter permitido reflexóes de melhoria das políticas públicas desenvolvidas e se refletido no processo de alocação interna do órgão. 
Notadamente, no entanto, não interferem na definição dos limites orçamentários que a Secretaria de Orçamento Federal distribui para cada um dos ministérios.

Assim, apesar de o PPA ter buscado apropriar várias funçóes de planejamento ao longo dos anos, o direcionamento do orçamento, conforme mandato constitucional, foi limitado tanto pelo arcabouço normativo fiscal, que confere mais peso aos ajustes de curto prazo do que aos objetivos de médio prazo, como pelos próprios processos orçamentários, ensimesmados. Além disso, o maior peso do Legislativo nos comandos do orçamento, com as emendas impositivas, também desloca a tomada de decisão orçamentária para mais longe da gestão do PPA. Essas características, mais que as fragilidades do próprio plano, que ainda persistem, são gargalos centrais do processo de planejamento e orçamento no Brasil atualmente.

\section{AS DISCUSSÕES RECENTES}

Essas características do arranjo de governança orçamentário brasileiro levam o PPA a uma posição marginal no processo de tomada de decisão alocativa. A constatação correta, no entanto, parte de um diagnóstico equivocado de que o problema seria o próprio instrumento ou, no máximo, as deficiências do planejamento, e não se considera o processo orçamentário como um todo.

Assim, observa-se, desde 2017, um movimento contraditório, marcado por estratégias distintas dos atores envolvidos na governança orçamentária no Brasil, que expressa a instabilidade do arranjo atual. De um lado, há um movimento que procura reforçar retoricamente as ideias de governança, coordenação e planejamento, de fato contestado pela garantia de destinação prioritária dos recursos por parte do Legislativo e pela flexibilização das demais vinculações orçamentárias referentes ao gasto primário, e, de outro, preserva-se o gasto financeiro do governo.

O primeiro movimento está relacionado com o fortalecimento da agenda de governança no Poder Executivo federal, que pode ser identificado em dois fatores principais, intrinsecamente vinculados entre si. Primeiramente, a atuação dos órgãos de controle, particularmente o Tribunal de Contas da União (TCU), que apresentou a agenda da governança ao Executivo no governo Michel Temer, que assumiu o poder no esteio de um processo de impeachment que tinha no processo de alteração orçamentária suas principais, ainda que controversas, bases motivacionais - além das manobras fiscais conhecidas como "pedaladas". Em seguida, a posição de organismos internacionais, como o Banco Mundial e a OCDE, com quem o Brasil estabelece um protocolo de adesão, surge como segundo fator de impulsionamento da agenda.

Cavalcante e Pires (2018) discutem o conceito de governança por trás da proposta do TCU, que se sustenta em um tripé composto por controle, estratégia e liderança. Para os autores, a apropriação pelo controle de um conceito trazido da iniciativa privada, em que a governança se traduzia em maior controle dos acionistas quanto às estratégias das empresas, ou a estratégia dos organismos internacionais de propagar uma receita de "boa governança" aos diferentes países, acrescenta mais dificuldades à aplicabilidade da agenda.

Esse processo é apropriado no governo federal por meio do Decreto nำ 9.203, de 22 de novembro de 2017, que institui a política de governança da administração pública federal, e do Projeto de Lei (PL) no 9.163/2017. Entre seus elementos, esses instrumentos buscaram responder ao $\$ 1^{\circ}$ do art. 174 da Constituição, que determina que a lei estabelecerá as diretrizes e as bases do planejamento do desenvolvimento nacional equilibrado. Nesse ponto, a política de governança 
propôs, acima do PPA, a instituição de uma Estratégia Nacional do Desenvolvimento Econômico e Social (Endes), para um horizonte de doze anos, ou três PPAs.

Embora o processo de adesão do Brasil à OCDE tenha sido continuado, a tramitação do PL perdeu fôlego na mudança de governo, que, com a assunção de Jair Bolsonaro, apostou em direção contrária. As Propostas de Emenda Constitucional (PECs) nos 187 e 188, apresentadas no final de 2019, tratam, entre outras coisas, da extinção do PPA, da transformação do orçamento anual em orçamento plurianual e da flexibilização das vinculaçóes constitucionais e legais de receitas a determinadas despesas, com a extinção de fundos públicos e a possibilidade de compensação dos gastos mínimos constitucionais nas áreas de saúde e educação.

Concretamente, a redução do papel do PPA no arranjo de governança orçamentária converge para a proposta de desvinculação dos gastos, distanciando a administração pública de compromissos com resultados para as políticas públicas. Com a impositividade das emendas parlamentares, a prioridade do Legislativo na orientação do orçamento é garantida. Ainda que a Endes venha a se estabelecer, nada indica que conseguirá apoiar as escolhas alocativas de curto prazo.

A CF/1988 representa grandes acordos sociais para direcionamento dos recursos administrados pelos governos em prol de setores considerados prioritários para a sociedade naquele momento. $\mathrm{O}$ avanço da flexibilização orçamentária, em conjunto com a fragilidade dos instrumentos de planejamento, traz o risco de se submeter o orçamento público a um equilíbrio político fugaz de curto prazo, com altos custos de longo prazo. A instabilidade das regras orçamentárias pode já ser um resultado parcial desse arranjo.

Ademais, diante da pandemia da Covid-19 e seus efeitos na economia, saúde e dinâmica social em geral no Brasil, era de se esperar que o governo revisitasse seu planejamento e fizesse uma revisão do PPA. A decisão de não o fazer revela, de um lado, a continuidade da estratégia de desvalorização e fragilização do instrumento e, de outro, a sua condição basicamente marginal na definição, coordenação, gestão ou explicitação das políticas públicas levadas a cabo pelo governo brasileiro, que, certamente, foram impactadas pelo novo cenário da crise pandêmica.

\section{CONCLUSÃO}

O PPA passou por uma série de adaptações ao longo dos anos, assumindo diferentes funções de planejamento, mas sua capacidade de orientar o orçamento restou limitada. Ao longo do artigo, argumentou-se que essa fragilidade não se deve apenas às características do próprio plano, que buscou constantemente novos espaços, mas também a um conjunto de características do processo orçamentário brasileiro.

A marca da atual instabilidade do arranjo de governança orçamentária brasileira também se projeta sobre o PPA, com a proposta de extinção do instrumento. O distanciamento do plano para com o orçamento reforçou sua condição de marginalidade já instituída a partir do regramento fiscal e das próprias condiçóes do processo orçamentário, que agora se consolidam com o cenário da crise pandêmica.

O ganho de poder pelo Legislativo na condução do orçamento, enquanto o Executivo busca diminuir as suas vinculações, completa um quadro que comprime o espaço do planejamento. $\mathrm{O}$ orçamento, dessa forma, corre o risco de ficar sujeito a negociaçóes de ocasião e equilíbrios de 
curto prazo. A fragilização do planejamento e a proposta de extinção do PPA são, muito mais que causas, um retrato da instabilidade da governança orçamentária no Brasil.

\section{REFERÊNCIAS}

ARANTES PAULO, Luiz Fernando. Plano Plurianual: teoria, prática e desafios para sua efetividade. Curitiba: Juruá, 2016.

AVELINO, Daniel Pitangueira de. Planejamento, orçamento e participação social. In: COUTO, Leandro Freitas; GIMENE, Márcio (Org.). Planejamento e orçamento público no Brasil. Brasília: ENAP, 2017.

BARCELOS, Carlos Leonardo Klein. Governança orçamentária e mudança institucional: o caso da norma geral de direito financeiro - Lei no 4.320/1964. 2012. Tese (Doutorado) - Universidade de Brasília, Brasília, 2012.

BARZELAY, Michael; SHVETS, Evgenia. Improvisando as práticas de planejamento estratégico centrado em projetos e sua implementação: o caso do Brasil em Ação. Revista de Administraçáo Pública, Rio de Janeiro, v. 39, n. 3, 2005.

BORGES, Ana Cláudia Silva Castro. Governança orçamentária e gasto público no Brasil: uma abordagem institucional do processo de definição da despesa em âmbito federal. 2015. Dissertação (Mestrado) - Universidade de Brasília, Brasília, 2015.

CAVALCANTE, Pedro; PIRES, Roberto. Apresentação: variedades de governança pública. Boletim de Análise Político-Institucional, Brasília: Ipea, n. 19, dez. 2018.

CAVALCANTE, Pedro; SILVA, Rafael Silveira. Metodologias aplicadas ao estudo das instituiçóes e do processo orçamentário na América Latina. Planejamento e Políticas Públicas, Brasília, n. 38, p. 37-67, 2012.

COUTO, Leandro Freitas; CARDOSO JUNIOR, José Celso. Governança orçamentária: transformaçóes e lacunas nas práticas de planejamento e orçamento no Brasil. Boletim de Análise Político-Institucional, Brasília: Ipea, n. 19, 2018.

A função dos Planos Plurianuais no direcionamento dos orçamentos anuais: avaliação da trajetória dos PPAs no cumprimento da sua missão constitucional e o lugar do PPA 2020-2023. Brasília: Ipea, 2020a. (Texto para Discusão, n. 2549).

. Planejamento governamental a partir da reforma do Estado. In: CAVALCANTE, Pedro; SILVA, Mauro (Org.). Reformas do Estado no Brasil: trajetórias, inovaçóes e desafios. Rio de Janeiro: Ipea, 2020b.

COUTO, Leandro Freitas; MAGALHÃES, Alvaro Pontes. Iniciativas, funçôes e estruturas de planejamento federal. Boletim de Análise Político-Institucional, Brasília: Ipea, n. 12, 2017. 
COUTO, Leandro Freitas; RODRIGUES, Júlia Alves Marinho. A transformação da Lei de Diretrizes Orçamentárias: impactos da Reforma Orçamentária de 2000 e da Lei de Responsabilidade Fiscal In: GIMENE, Márcio. Planejamento, orçamento e sustentabilidade fiscal. Brasília: Assecor, 2020.

GARCIA, Ronaldo Coutinho. A reorganização do processo de planejamento do governo federal: o PPA 2000-2003. In: CARDOSO JUNIOR, José Celso; CUNHA, Alexandre dos Santos (Org.). Planejamento e avaliaçáo de políticas públicas. Brasília: Ipea, 2015.

RODRIGUES, Júlia Alves Marinho. Orçamento impositivo: diferenças de perspectiva entre os Poderes Legislativo e Executivo. In: COUTO, Leandro; GIMENE, Márcio (Org.). Planejamento e orçamento público no Brasil. Brasília: Enap, 2017.

RODRIGUES, Júlia Alves Marinho; XAVIER, Elaine de Melo. A transversalidade e os Planos Plurianuais: a história contada por três ciclos de elaboração e gestão do plano federal. Revista Brasileira de Administraçáo Política, Salvador: EAUFBA, v. 10, n. 2, out. 2017. 
